\title{
Venovenous extracorporeal membrane oxygenation and single-ventricle patients: A good match?
}

\author{
Paul J. Chai, MD
}

\author{
From the Department of Surgery, Columbia University Medical Center, New York, NY. \\ Disclosures: Author has nothing to disclose with regard to commercial support. \\ Received for publication March 17, 2016; accepted for publication March 17, 2016. \\ Address for reprints: Paul J. Chai, MD, Department of Surgery, Columbia University Medical Center, 161 Fort \\ Washington Ave, New York, NY 10032 (E-mail: pjc2164@cumc.columbia.edu). \\ J Thorac Cardiovasc Surg 2016;151:1737 \\ $0022-5223 / \$ 36.00$ \\ Copyright (C) 2016 Published by Elsevier Inc. on behalf of The American Association for Thoracic Surgery \\ http://dx.doi.org/10.1016/j.jtcvs.2016.03.030
}

Venovenous (VV) extracorporeal membrane oxygenation (ECMO) is an alternative method of extracorporeal support for patients without cardiac failure. Advantages include preservation of the carotid artery, pulsatile blood flow, potentially improved (oxygenated) coronary blood flow, and the potential for the lungs to act as a filter for thromboemboli from the circuit. VV ECMO has been shown to have equivalent results compared with venoarterial (VA) ECMO in select populations. ${ }^{1}$ Its use in postoperative cardiac surgical patients is limited. ${ }^{2}$ Aydin and colleagues $^{3}$ used data from the Extracorporeal Life Support Organization database to look at the characteristics and outcomes of single-ventricle patients treated with VV ECMO.

Single-ventricle patients may experience primary respiratory failure more often than biventricular cardiac surgical patients and so VV ECMO for single-ventricle patients who are candidates is an intriguing option. Advantages of $\mathrm{VV}$ ECMO in single-ventricle patients include preservation of pulsatile flow and decreased afterload on the heart. Avoiding cannulation of the carotid artery also mitigates any potential runoff down an aortopulmonary shunt and eliminates the possibility of inadvertent advancement of the arterial cannula down the shunt itself.

In the study by Aydin and colleagues ${ }^{3} 89$ patients with single-ventricle anatomy had VV ECMO. Indications were respiratory failure in $63 \%$ and cardiac failure for $32 \%$. Survival to discharge was $48 \%$, suggesting that single-ventricle patients with respiratory failure may be successfully supported with VV ECMO alone. This is the largest amount of published data on single-ventricle patients managed with VV ECMO. Despite this, there are significant limitations that must be taken into account when considering this article. ${ }^{3}$ Thirty-seven percent of patients began VV ECMO for "cardiac reasons." Unfortunately, this group of patients remains somewhat of a mystery, because the database holds no further information on what this exactly means. It could be a chicken or the egg arise.

\section{References} Surg. 1993;28:530-5.

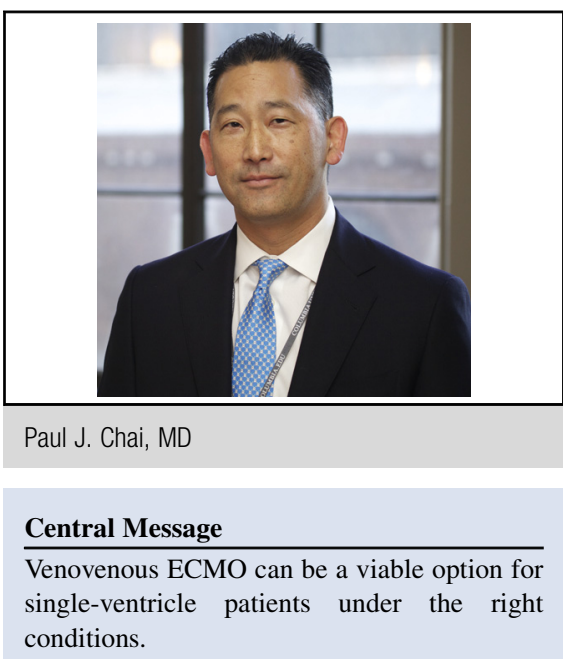

See Article page 1730 .

See Editorials page 1444 and 1446.

phenomenon because respiratory failure can often lead to cardiac failure, and so these patients may be miscoded. It is also difficult to know if any of the VV ECMO patients subsequently required conversion to VA ECMO because this is not indicated in the article.

Comparisons between VA and VV ECMO in this cohort of patients is difficult because the indications for VA or VV ECMO are likely very different. It is also not known if there were institutional tendencies to place patients receiving one form of ECMO over another. Nevertheless, the authors have demonstrated that VV ECMO for single-ventricle patients can have good outcomes in patients who are candidates and should be considered a viable option should the need

1. Anderson HL, Snedecor SM, Otsu T, Bartlett RH. Multicenter comparison of conventional venoarterial access versus venovenous double-lumen catheter access in newborn infants undergoing extracorporeal membrane oxygenation. J Pediatr

2. Ryan LP, Montenegro LM, Bird GL, Gruber PJ. Successful support and separation from veno-venous extracorporeal membrane oxygenation support in a threemonth old patient following bidirectional Glenn procedure. Interact Cardiovasc Thorac Surg. 2010;11:496-8.

3. Aydin SI, Duffy M, Rodriguez D, Rycus PT, Freidman P, Thiagarajan RR, et al Venovenous extracorporeal membrane oxygenation for single ventricle patients: a registry report. J Thorac Cardiovasc Surg. 2016;151:1730-6. 